\title{
Probability of Vitamin D Deficiency by Body Weight and Race/Ethnicity
}

\author{
Tom Weishaar, MA, Sonali Rajan, EdD, and Bryan Keller, PhD
}

Introduction: While most physicians recognize that vitamin D status varies by skin color because darker skin requires more light to synthesize vitamin D than lighter skin, the importance of body weight to vitamin D status is a newer, less recognized, finding. The purpose of this study was to use nationally representative US data to determine the probability of vitamin D deficiency by body weight and skin color.

Methods: Using data for individuals age $\geq 6$ years from the 2001 to 2010 cycles of the US National Health and Nutrition Examination Survey, we calculated the effect of skin color, body weight, and age on vitamin D status. We determined the probability of deficiency within the normal range of body weight for 3 race/ethnicity groups at 3 target levels of 25 -hydroxyvitamin $D$.

Results: Darker skin colors and heavier body weights are independently and significantly associated with poorer vitamin D status. We report graphically the probability of vitamin D deficiency by body weight and skin color at vitamin $D$ targets of 20 and $30 \mathrm{ng} / \mathrm{mL}$.

Conclusion: The effects of skin color and body weight on vitamin D status are large both statistically and clinically. Knowledge of these effects may facilitate diagnosis of vitamin D deficiency. ( $\mathrm{J}$ Am Board Fam Med 2016;29:226-232.)

Keywords: Minority Health, Nutritional Sciences, Preventive Medicine, Vitamin D

Vitamin D may be more important to human health than previously recognized. Inside cells, gene activity is controlled by nuclear receptors. The vitamin D nuclear receptor responds to at least 3 vitamin $\mathrm{D}$ compounds in humans: the storage form 25-hydroxyvitamin D $(25[\mathrm{OH}] \mathrm{D})$, the classically active form 1,25-dihydroxyvitamin $\mathrm{D}$, and the breakdown form 24R,25-dihydroxyvitamin D. With some overlap, each form regulates different genes. ${ }^{1}$ Estimates of the vitamin D receptor's importance in humans vary, but it seems to control,

This article was externally peer reviewed.

Submitted 10 August 2015; revised 12 November 2015; accepted 17 November 2015.

From the Department of Health and Behavior Studies (TW, SR) and the Department of Human Development (BK), Teachers College, Columbia University, New York, NY.

Funding: none.

Conflict of interest: TW has an intellectual passion about vitamin D and has an unpaid, volunteer relationship with the Vitamin D Council. The other authors have no conflicts of interest.

Corresponding author: Tom Weishaar, MA, 501 W 120th St, \#8W, New York, NY 10027 (E-mail: jtw2117@columbia. edu). either directly or indirectly, up to 2000 of the approximately 20,000 to 25,000 human genes. ${ }^{2}$

Research suggests that the impact of vitamin D status on human health is large enough to have played a remarkable role in human evolution. Anthropologists regard human skin color as an evolutionary adaptation to ultraviolet light. ${ }^{3}$ The theory posits that dark skin is protective against the intense sunlight at the equator but that at other latitudes individuals with lighter skin have the evolutionary advantage of better health. This is because their sunlight-dependent vitamin D concentrations are closer to those of the ancestral, dark-skinned, equatorial population. Thus the geographic intensity of sunlight and its health impact produce the spectrum of human skin colors we see as we move away from the equator.

From a health perspective, this theory implies that health disparities are found in all populations with diverse skin colors. ${ }^{3-5}$ In areas of intense sunlight, those with lighter skin are disadvantaged. In areas like the United States, those with darker skin have poorer health. Yet the theory also implies that health professionals can readily take action to alle- 
Table 1. Mean 25-Hydroxyvitamin D Concentrations among the US Population Aged 6 Years and Older, 2001-2010, with Percentage Breakouts by Vitamin D Status

\begin{tabular}{|c|c|c|c|c|c|}
\hline & \multirow[b]{2}{*}{ Unweighted No. } & \multirow{2}{*}{$\begin{array}{c}25(\mathrm{OH}) \mathrm{D}(\mathrm{ng} / \mathrm{mL}) \\
\text { Mean }(\mathrm{SE})\end{array}$} & \multicolumn{3}{|c|}{$\begin{array}{c}\text { Percentage (SE) of Population by } \\
25(\mathrm{OH}) \mathrm{D} \text { Status }\end{array}$} \\
\hline & & & $<20 \mathrm{ng} / \mathrm{mL}$ & $20-<30 \mathrm{ng} / \mathrm{mL}$ & $\geq 30 \mathrm{ng} / \mathrm{mL}$ \\
\hline Population & 36,434 & $25.9(0.23)$ & $27(1.0)$ & $43(0.6)$ & $30(0.9)$ \\
\hline \multicolumn{6}{|l|}{ Sex } \\
\hline Male & 17,897 & $25.8(0.23)$ & $25(1.0)$ & $46(0.7)$ & $29(1.0)$ \\
\hline Female & 18,537 & $26.0(0.24)$ & $30(1.0)$ & $39(0.7)$ & $31(0.9)$ \\
\hline \multicolumn{6}{|l|}{ Race/ethnicity } \\
\hline Non-Hispanic white & 15,652 & $28.3(0.22)$ & $17(0.7)$ & $44(0.7)$ & $39(1.0)$ \\
\hline Mexican-American & 8,528 & $21.9(0.26)$ & $41(1.5)$ & $47(1.0)$ & $13(0.8)$ \\
\hline Non-Hispanic black & 8,267 & $17.4(0.27)$ & $68(1.5)$ & $26(1.2)$ & $6(0.5)$ \\
\hline All other & 3,987 & $22.6(0.29)$ & $39(1.9)$ & $45(1.4)$ & $16(1.0)$ \\
\hline \multicolumn{6}{|l|}{ Age (years) } \\
\hline $6-<10$ & 3,023 & $29.1(0.34)$ & $10(0.8)$ & $49(1.5)$ & $41(1.9)$ \\
\hline $10-<20$ & 9,841 & $25.8(0.30)$ & $25(1.3)$ & $47(1.1)$ & $28(1.2)$ \\
\hline $20-<40$ & 8,214 & $25.4(0.28)$ & $31(1.3)$ & $41(0.8)$ & $29(1.1)$ \\
\hline $40-<60$ & 7,385 & $25.7(0.26)$ & $28(1.2)$ & $42(1.0)$ & $30(1.1)$ \\
\hline$\geq 60$ & 7,971 & $26.2(0.24)$ & $27(0.8)$ & $41(0.7)$ & $32(1.1)$ \\
\hline \multicolumn{6}{|l|}{ Weight (kg) } \\
\hline$<25$ & 1,047 & $30.4(0.44)$ & $6(0.8)$ & $46(2.3)$ & $48(2.5)$ \\
\hline $25-<50$ & 5,068 & $27.1(0.31)$ & $19(1.2)$ & $47(1.4)$ & $34(1.5)$ \\
\hline $50-<75$ & 14,785 & $27.0(0.23)$ & $24(1.0)$ & $41(0.7)$ & $35(0.9)$ \\
\hline $75-<100$ & 11,435 & $25.3(0.24)$ & $29(1.1)$ & $43(0.8)$ & $28(1.0)$ \\
\hline $100-<125$ & 3,237 & $23.4(0.31)$ & $36(1.7)$ & $42(1.6)$ & $22(1.4)$ \\
\hline$\geq 125$ & 862 & $20.3(0.45)$ & $50(2.7)$ & $39(2.3)$ & $10(1.6)$ \\
\hline
\end{tabular}

25(OH)D, 25-hydroxyvitamin D; SE, standard error.

viate these health disparities: sun protection for those with light skin where sunlight is intense, and vitamin D supplements for those with dark skin everywhere else.

As the theory suggests, at the latitude of the United States, those with darker skin colors actually have much lower vitamin D concentrations than those with lighter skin. For US individuals age 6 years and older, average $25(\mathrm{OH}) \mathrm{D}$ concentrations are $17.4 \mathrm{ng} / \mathrm{mL}$ for non-Hispanic blacks, whereas Mexican Americans average 26\% higher at $21.9 \mathrm{ng} / \mathrm{mL}$ and non-Hispanic whites average $62 \%$ higher at $28.3 \mathrm{ng} / \mathrm{mL}$ (Table 1 ). In terms of sun protection, on the other hand, invasive melanoma is 24.7 times more likely among US non-Hispanic whites than US blacks. ${ }^{6}$ Ghanaian farmers living near the equator $\left(6^{\circ} \mathrm{N}\right)$ have an average concentration of $30 \mathrm{ng} / \mathrm{mL}^{7}$ while dark-skinned people living traditionally in east Africa ( $\left.4^{\circ} \mathrm{S}\right)$, who provide the best estimate of vitamin $\mathrm{D}$ concentrations over the course of human evolution, have an average concentration of $46 \mathrm{ng} / \mathrm{mL}{ }^{8}$
In addition to skin color, body weight has an important impact on vitamin $\mathrm{D}$ status because of the effect of dilution. ${ }^{9-11}$ Vitamin D is measured as a concentration (weight/volume), so larger individuals need more vitamin D to obtain the same concentration as smaller individuals. Research suggests that body weight is a better index of this dilution than body mass index. ${ }^{9-11}$ Many of the diseases and conditions associated with vitamin $\mathrm{D}$ deficiency are also associated with race- and obesity-related health problems. Given the potential benefits of optimal vitamin D status and the large impact of skin color and body weight on $25(\mathrm{OH}) \mathrm{D}$ status, we focused our research on calculating the probability of vitamin $\mathrm{D}$ deficiency by body weight and skin color using nationally representative US data.

\section{Methods}

We used data from a subset of the nationally representative continuous version of the US National Health and Nutrition Examination Survey 
(NHANES), which is collected by the National Center for Health Statistics, a unit of the Centers for Disease Control and Prevention. ${ }^{12}$ The National Center for Health Statistics Ethics Review Board approved the NHANES data collection protocols, and the institutional review board of the Teachers College, Columbia University, approved our work with NHANES. NHANES researchers collect data on a 2-year cycle, selecting individuals using complex survey methodology, which creates a nationally representative random sample of the noninstitutionalized US population. Details of the complex NHANES design are presented elsewhere. ${ }^{13}$

Five 2-year cycles of NHANES (from 2001 to 2010) include serum $25(\mathrm{OH}) \mathrm{D}$ measures for individuals age 6 years and above. Data for those older than 1 year are also available in all but the first of these 5 cycles, 2001 to 2002. In this analysis we did not use any of the data for 1 - to 5 -year-olds so that we could include the 2001-2002 data. For the first 3 cycles, assays were completed using the DiaSorin RIA kit (Saluggia, Italy). For the final 2 cycles, NHANES researchers used standardized liquid chromatography-tandem mass spectrometry traceable to National Institute of Standards reference materials, which only recently became available (http://www.nist.gov/mml/csd/vitamind_071409.cfm). NHANES researchers adjusted values from the DiaSorin assays upward to more closely match the standardized assay. ${ }^{14}$ This analysis uses the adjusted serum $25(\mathrm{OH}) \mathrm{D}$ values. All values were converted from nanomoles per liter to nanograms per milliliter, the serum $25(\mathrm{OH}) \mathrm{D}$ reporting standard used by US laboratories, by dividing by 2.496 .

The NHANES race/ethnicity variable provides nationally representative data for non-Hispanic blacks, Mexican Americans, and non-Hispanic whites, which we use as a proxy for skin color. Our analysis also included sex, age in years, body weight in kilograms, and the appropriate complex survey weight for each case. After listwise deletion of cases with missing data, NHANES provided 36,434 (unweighted) cases for our analysis.

We used the statistical program $\mathrm{R}$, version 3.2.1 (R Foundation for Statistical Computing, Vienna, Austria) and its Survey package (version 3.30), which is appropriate for analyzing complex survey data. ${ }^{15}$ We created Figure 1 using nonlinear logistic regression based on natural B-splines. That analysis provides the estimated probability that individuals are deficient at various serum $25(\mathrm{OH}) \mathrm{D}$ targets across typical body weights by skin color, as well as estimated standard errors, from which we calculated $95 \%$ confidence intervals.

\section{Results}

Table 1 shows the demographic characteristics of our data set, which is representative of the noninstitutionalized US population aged $\geq 6$ years in the 2001 to 2010 time frame. ${ }^{13,14,16}$ The first column shows the unweighted number of subjects in each group (some groups were oversampled compared with their presence in the population; weights are used to correct for this and other issues related to obtaining the nationally representative estimates presented in the remaining columns). This is followed by the mean $25(\mathrm{OH}) \mathrm{D}$ concentration of the group and its standard error. The following columns show the percentage distribution of each line in the table by 3 vitamin $\mathrm{D}$ status groups. For example, considering the column showing $25(\mathrm{OH}) \mathrm{D}$ status $<20 \mathrm{ng} / \mathrm{mL}$, note that while $27 \%$ of the entire population is in this deficient group, it includes $68 \%$ of non-Hispanic blacks and $50 \%$ of those who weigh $>125 \mathrm{~kg}$. In contrast to the very large differences by weight and skin color, the differences by sex and by age after childhood are unremarkable.

The 2 plots in Figure 1 show the probability that an individual in the US population is vitamin D deficient at two target levels of deficiency-below 20 and below $30 \mathrm{ng} / \mathrm{mL}$ - by body weight and skin color. The plots also show $95 \%$ confidence intervals for the probability estimates. Where the confidence intervals are wider, there are fewer individuals in the population with the corresponding body weight and skin color. Non-Hispanic blacks are more likely to be deficient at all weight levels, followed by Mexican Americans. Figure 1A shows the probability of deficiency at a target of below 20 $\mathrm{ng} / \mathrm{mL}$. In Figure 1B the deficiency target is below $30 \mathrm{ng} / \mathrm{mL}$. At a target of below $40 \mathrm{ng} / \mathrm{mL}$, all 3 lines hug the top of the chart between $85 \%$ and $100 \%$ at all points, indicating that everyone in the US population who is not already using ample vitamin $\mathrm{D}$ supplementation would need to do so, so that plot is not shown.

\section{Discussion}

We present results at 3 different $25(\mathrm{OH}) \mathrm{D}$ concentrations because the optimal concentration of $25(\mathrm{OH}) \mathrm{D}$ in humans is currently controversial. In 
Figure 1. Probability of vitamin D deficiency by body weight and skin color at 2 target 25-hydroxyvitamin D (25[OH]D) concentrations: below $20 \mathrm{ng} / \mathrm{mL}$ (A) and below $30 \mathrm{ng} / \mathrm{mL}$ (B). If vitamin D deficiency is defined as a 25(OH)D concentration below $40 \mathrm{ng} / \mathrm{mL}$, all 3 lines hug the top of the graph, so that figure is not shown. Bands indicate $95 \%$ confidence intervals for the probability of deficiency.
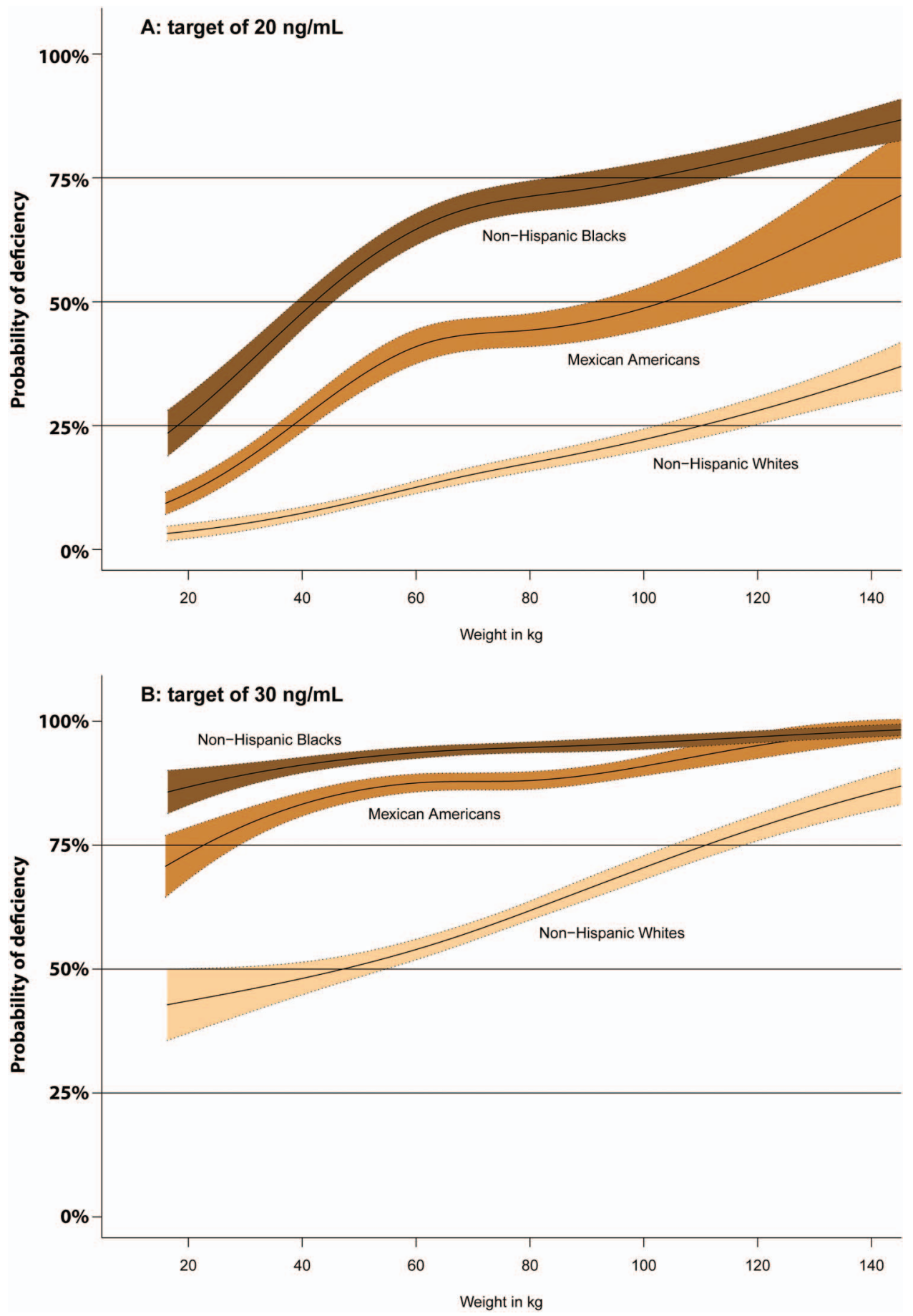

part this is because, at the highest suggested concentration of $40 \mathrm{ng} / \mathrm{mL}$, virtually the entire US population would be deemed vitamin $\mathrm{D}$ deficient. Even at a suggested concentration of $30 \mathrm{ng} / \mathrm{mL}$, virtually all adult non-Hispanic blacks would be considered vitamin D deficient. Moreover, some research suggests that the optimal concentration of $25(\mathrm{OH}) \mathrm{D}$ is not the same in the context of different diseases. ${ }^{17}$ 
In late 2010 the Institute of Medicine's Committee to Review Dietary Intakes for Vitamin D and Calcium suggested $20 \mathrm{ng} / \mathrm{mL}$ as an appropriate average population concentration for bone health, but said more randomized controlled trials (RCTs) would have to be conducted before it could determine an appropriate level for the other functions of vitamin D. ${ }^{18}$ The Endocrine Society later released RCT-based guidelines recommending a minimum of $30 \mathrm{ng} / \mathrm{mL} .{ }^{19}$ The Vitamin D Council says that epidemiologic data suggest concentrations in the 50 - to $80-\mathrm{ng} / \mathrm{mL}$ range are sufficient. ${ }^{20}$

In addition to body weight and skin color, other determinants of vitamin D status include season, sunlight intensity and exposure, and use of vitamin D supplements. ${ }^{21-24}$ Research suggests that low vitamin $\mathrm{D}$ in obese women is not caused by reduced sun exposure. ${ }^{25}$ In addition, US health professionals consider age to be the primary determinant of vitamin D status. For example, the Institute of Medicine's Committee to Review Dietary Intakes for Vitamin D and Calcium recommended different vitamin D intakes for those $<1$ year of age (400 $\mathrm{IU} /$ day), those ages 1 to 70 years (600 IU/day), and those over age 70 years ( $800 \mathrm{IU} /$ day), but made no recommendations by weight or skin color. ${ }^{18} \mathrm{Al}-$ though it is generally known among health professionals that African Americans have lower vitamin D concentrations than white Americans, the impact of skin color on vitamin D status is considered to be unremarkable compared with the impact of age. The impact of body weight on vitamin $\mathrm{D}$ status is a more recent discovery that is still unknown to most health professionals. Furthermore, in an article accepted for publication in Public Health Nutrition, our research group has shown that the apparent effect of age on vitamin D status is quite small after controlling for body weight.

Skin color is important to dosing only because those with darker skin have lower baseline vitamin D concentrations. $^{26,27}$ A recently reported 3-month dose-response study of African Americans by $\mathrm{Ng}$ and colleagues $^{28}$ did not consider or report body weight, but the average body mass index of the participants was $31.2 \mathrm{~kg} / \mathrm{m}^{2}$. Three treatment groups received doses of 1000, 2000, and 4000 IU/day and achieved 25(OH)D concentrations of 29.7 (up 13.5 from this group's baseline), 34.8 (up 20.9), and $45.9 \mathrm{ng} / \mathrm{mL}$ (up $30.2 \mathrm{ng} / \mathrm{mL}$ ), respectively.

Body weight, on the other hand, is important to dosing both because of lower baseline values and because heavier individuals have a lower response to a given dose than lighter individuals. Drincic and colleagues, ${ }^{9}$ who have been at the forefront of emphasizing the importance of body weight to vitamin $\mathrm{D}$ status, have done a study using doses of 1000, 5000, and 10,000 IU for 21 weeks in 62 obese white subjects. ${ }^{29}$ They suggest a reasonable starting dose of vitamin $\mathrm{D}_{3}$ is $2.5 \mathrm{IU} / \mathrm{kg}$ body weight $/ 1 \mathrm{ng} / \mathrm{mL}$ of desired increase in $25(\mathrm{OH}) \mathrm{D}$ concentration. Singh and Bonham ${ }^{27}$ more recently published a detailed dosing formula based on results seen in actual health care settings. In the United States vitamin $\mathrm{D}_{3}$ supplements are typically available over the counter in 5000-, 2000-, 1000-IU, and smaller doses; consequently, a calculated result must be adjusted to a workable supplement size before advising the patient. Vitamin $\mathrm{D}_{3}$ is the animal form of vitamin $\mathrm{D}$ and is also produced by some plants. ${ }^{30}$ Vitamin $\mathrm{D}_{2}$, which is used in formulations available by prescription in the United States, is produced by yeast and fungi and is less effective at increasing $25(\mathrm{OH}) \mathrm{D}$ concentrations. ${ }^{11}$ Drincic and colleagues also emphasize that there is a very large amount of individual variation in response to $25(\mathrm{OH}) \mathrm{D}$ dose. They suggest that clinicians should rely on a subsequent serum $25(\mathrm{OH}) \mathrm{D}$ test to assess the accuracy of a calculated dose.

Until recently there has been a great deal of concern related to vitamin $\mathrm{D}$ toxicity in the context of supplementation. However, actual cases of vitamin D toxicity are extremely rare and typically result in complete recovery after the source of excessive vitamin $\mathrm{D}$ is discovered and removed. ${ }^{31,32}$ In general, reported cases result from compounding or manufacturing errors that could happen with any drug or supplement and are not specific to vitamin D. Concerns about vitamin D's toxicity date to the 1950s, when unusual cases of idiopathic infantile hypercalcemia occurred soon after foods were fortified with vitamin $\mathrm{D}$. Recent genetic studies have clarified that idiopathic infantile hypercalcemia is related to a mutation in the CYP24A1 gene, which produces the enzyme that metabolizes 25(OH)D and 1,25-dihydroxyvitamin D. ${ }^{33}$ Individuals with this mutation or with diseases known to lead to high calcium concentrations, such as sarcoidosis and lymphoma, should receive vitamin D supplementation only under medical supervision.

Moreover, many individuals do not follow professional advice to take vitamin D supplements. Research to date has found only 1 technique that has a major impact on supplement adherence: pro- 
viding the recommended supplement dose on a prescription form. ${ }^{34}$

\section{Limitations}

US health policy panels have said that it is premature to recommend that African Americans increase their vitamin $\mathrm{D}$ concentrations because of a lack of evidence from RCTs. ${ }^{18}$ On the other hand, such panels rely almost entirely on epidemiologic evidence to recommend sun protection, which primarily benefits those with light skin. ${ }^{6}$ A reasonable approach would be to use the same standard of evidence for all sunlight-related health consequences rather than different standards for different groups.

In 2013 Powe and colleagues ${ }^{35}$ published an article in the New England Fournal of Medicine suggesting that

low total 25(OH)D levels do not uniformly indicate vitamin $\mathrm{D}$ deficiency and call into question routine supplementation in persons with low levels of both total $25(\mathrm{OH}) \mathrm{D}$ and vitamin $\mathrm{D}$ binding protein [that is, African Americans] who lack other traditional manifestations of this condition. ... Labeling the majority of the black participants as vitamin D-deficient would be inconsistent with the observation that they had higher bone mineral density, higher calcium levels, and only slightly higher parathyroid hormone levels than their white counterparts.

However, their conclusions may be premature. The higher bone mineral densities and calcium concentrations among US blacks were well known ${ }^{36}$ before the study by Powe et al. ${ }^{35}$ They had been and are considered a paradox. The results of the study by Powe et al do not explain this paradox, although other theories do. ${ }^{37}$ Powe et al's theory of bioavailable vitamin $\mathrm{D}$ is only one of multiple theories suggesting how vitamin D compounds cross the cellular membrane-all of which may be true. Individuals with dark skin living near the equator in Africa have much higher vitamin D concentrations than any group in the United States, indicating that sunlight intensity accounts for the higher concentrations. The study by Powe et al suggests instead that the genetics of vitamin $\mathrm{D}$ binding protein in African-origin populations accounts for the low vitamin D concentrations found in African Americans. In that case we would expect to find those same low concentrations in Africa, but we do not. ${ }^{7,8} \mathrm{Im}$ portantly, there is evidence of an association between vitamin D status and US racial health disparities. ${ }^{3-5}$ Finally, Powe et al limited their discussion to bone health and did not consider any other effects vitamin D may have on human health.

The results of this study apply to the US population and should not be assumed to be relevant in other countries. In addition, because researchers have only recently realized the importance of body weight to vitamin $\mathrm{D}$ dosage requirements, there are currently no vitamin $\mathrm{D}$ dose-response studies in the literature that combine both body weight and skin color. Additional research on larger groups, covering a wider range of body weights and baseline and target vitamin D concentrations, is needed to clarify dosage recommendations.

\section{Conclusions}

The effects of skin color and body weight on vitamin D status are large, both statistically and clinically. At typical target concentrations of deficiency (below 20 or below $30 \mathrm{ng} / \mathrm{mL}$ ), those with darker skin colors or heavier body weights have a higher probability of being vitamin $\mathrm{D}$ deficient. Knowledge of these effects may facilitate the diagnosis of vitamin $\mathrm{D}$ deficiency.

\section{References}

1. Tuohimaa P, Wang JH, Khan S, et al. Gene expression profiles in human and mouse primary cells provide new insights into the differential actions of vitamin D metabolites. Plos One 2013;8:e75338.

2. Hossein-Nezhad A, Holick MF. Vitamin D for health: a global perspective. Mayo Clin Proc 2013; 88:720-55.

3. Jablonski NG. The evolution of human skin colouration and its relevance to health in the modern world. J R Coll Physicians Edinb 2012;42:58-63.

4. Weishaar T, Vergili JM. Vitamin D status is a biological determinant of health disparities. J Acad Nutr Diet 2013;113:643-51.

5. Diaz VA, Mainous AG 3rd, Carek PJ, Wessell AM, Everett CJ. The association of vitamin D deficiency and insufficiency with diabetic nephropathy: implications for health disparities. J Am Board Fam Med 2009;22:521-7.

6. US Department of Health and Human Services. The Surgeon General's call to action to prevent skin cancer. Washington, DC: Office of the Surgeon General; 2014.

7. Durazo-Arvizu RA, Camacho P, Bovet P, et al. 25Hydroxyvitamin D in African-origin populations at varying latitudes challenges the construct of a physiologic norm. Am J Clin Nutr 2014;100:908-14.

8. Luxwolda MF, Kuipers RS, Kema IP, Dijck-Brouwer DA, Muskiet FA. Traditionally living popula- 
tions in East Africa have a mean serum 25-hydroxyvitamin D concentration of $115 \mathrm{nmol} / \mathrm{l}$. Br J Nutr 2012;108:1557-61.

9. Drincic AT, Armas LA, Van Diest EE, Heaney RP. Volumetric dilution, rather than sequestration best explains the low vitamin D status of obesity. Obesity (Silver Spring) 2012;20:1444-8.

10. Vimaleswaran KS, Berry DJ, Lu C, et al. Causal relationship between obesity and vitamin $\mathrm{D}$ status: bi-directional Mendelian randomization analysis of multiple cohorts. PLoS Med 2013;10:e1001383.

11. Zittermann A, Ernst JB, Gummert JF, Borgermann J. Vitamin D supplementation, body weight and human serum 25-hydroxyvitamin D response: a systematic review. Eur J Nutr 2014;53:367-74.

12. National Health and Nutrition Examination Survey Data. 1999-2010. Atlanta: Centers for Disease Control and Prevention. Available from: http://www.cdc. gov/nchs/nhanes.htm. Accessed October 27, 2015.

13. Zipf G, Chiappa M, Porter KS, Ostchega Y, Lewis BG, Dostal J. National Health and Nutrition Examination Survey: plan and operations, 1999-2010. Vital Health Stat $12013 ;(56): 1-37$.

14. National Center for Health Statistics. Analytical note for 25-hydroxyvitamin D data analysis using NHANES III (1988-1994), NHANES 2001-2006, and NHANES 2007-2010 (October 2015). Atlanta: Centers for Disease Control and Prevention (CDC). Available from: http:// wwwn.cdc.gov/Nchs/Nhanes/VitaminD/AnalyticalNote. aspx. Accessed October 27, 2015.

15. Lumley T. Analysis of complex survey samples. J Stat Softw 2004;9:1-19.

16. Johnson CL, Paulose-Ram R, Ogden CL, et al. NHANES analytic guidelines 1999-2010. Vital Health Stat 2 2013;(161):1-24.

17. Spedding S, Vanlint S, Morris H, Scragg R. Does vitamin $\mathrm{D}$ sufficiency equate to a single serum 25-hydroxyvitamin D level or are different levels required for non-skeletal diseases? Nutrients 2013;5:5127-39.

18. Ross AC, Taylor C, Yaktine A, Del Valle H. Dietary reference intakes for calcium and vitamin D. Washington, DC: National Academies Press; 2011.

19. Holick MF, Binkley NC, Bischoff-Ferrari HA, et al. Evaluation, treatment, and prevention of vitamin D deficiency: an Endocrine Society clinical practice guideline. J Clin Endocrinol Metab 2011;96:1911-30.

20. Vitamin D Council. For health professionals: position statement of supplementation, blood levels and sun exposure. January 12, 2010. Available from: http:// www.vitamindcouncil.org/further-topics/for-healthprofessionals-position-statement-on-supplementationblood-levels-and-sun-exposure/. Accessed July 11, 2015.

21. Rockell JE, Green TJ, Skeaff CM, et al. Season and ethnicity are determinants of serum 25-hydroxyvitamin D concentrations in New Zealand children aged 5-14 y. J Nutr 2005;135:2602-8.

22. Rizzoli R, Eisman JA, Norquist J, et al. Risk factors for vitamin D inadequacy among women with osteoporosis: an international epidemiological study. Int J Clin Pract 2006;60:1013-9.

23. Chan J, Jaceldo-Siegl K, Fraser GE. Determinants of serum 25-hydroxyvitamin D levels in a nationwide cohort of blacks and non-Hispanic whites. Cancer Causes Control 2010;21:501-11.

24. Kimlin MG, Lucas RM, Harrison SL, et al. The contributions of solar ultraviolet radiation exposure and other determinants to serum 25-hydroxyvitamin $\mathrm{D}$ concentrations in Australian adults: the AusD Study. Am J Epidemiol 2014;179:864-74.

25. Macdonald HM, Mavroeidi A, Aucott LA, et al. Skin color change in Caucasian postmenopausal women predicts summer-winter change in 25-hydroxyvitamin D: findings from the ANSAViD Cohort Study. J Clin Endocrinol Metab 2011;96:1677-86.

26. Aloia JF, Patel M, DiMaano R, et al. Vitamin D intake to attain a desired serum 25-hydroxyvitamin D concentration. Am J Clin Nutr 2008;87:1952-8.

27. Singh G, Bonham AJ. A predictive equation to guide vitamin D replacement dose in patients. J Am Board Fam Med 2014;27:495-509.

28. $\mathrm{Ng} \mathrm{K}$, Scott JB, Drake BF, et al. Dose response to vitamin $\mathrm{D}$ supplementation in African Americans: results of a 4-arm, randomized, placebo-controlled trial. Am J Clin Nutr 2014;99:587-98.

29. Drincic A, Fuller E, Heaney RP, Armas LA. 25 Hydroxyvitamin D response to graded vitamin $\mathrm{D}(3)$ supplementation among obese adults. J Clin Endocrinol Metab 2013;98:4845-51.

30. Jäpelt RB, Jakobsen J. Vitamin D in plants: a review of occurrence, analysis, and biosynthesis. Front Plant Sci 2013;4:136.

31. Spiller HA, Good TF, Spiller NE, Aleguas A. Vitamin D exposures reported to US poison centers 2000-2014: temporal trends and outcomes. Hum Exp Toxicol 2015 October 30. [Epub ahead of print]

32. Vogiatzi MG, Jacobson-Dickman E, Deboer MD. Vitamin D supplementation and risk of toxicity in pediatrics: A review of current literature. J Clin Endocrinol Metab 2014;99:1132-41.

33. Schlingmann KP, Kaufmann M, Weber S, et al. Mutations in CYP24A1 and idiopathic infantile hypercalcemia. N Engl J Med 2011;365:410-21.

34. Hill DA, Cacciatore M, Lamvu GM. Electronic prescribing influence on calcium supplementation: a randomized controlled trial. Am J Obstet Gynecol 2010;202:236.e1-5.

35. Powe CE, Evans MK, Wenger J, et al. Vitamin D-binding protein and vitamin $\mathrm{D}$ status of black Americans and white Americans. N Engl J Med 2013;369:1991-2000.

36. Weinstein RS, Bell NH. Diminished rates of boneformation in normal black adults. $\mathrm{N}$ Engl J Med 1988;319:1698-701.

37. Heaney RP. Ethnicity, bone status, and the calcium requirement. Nutr Res 2002;22:153-78. 